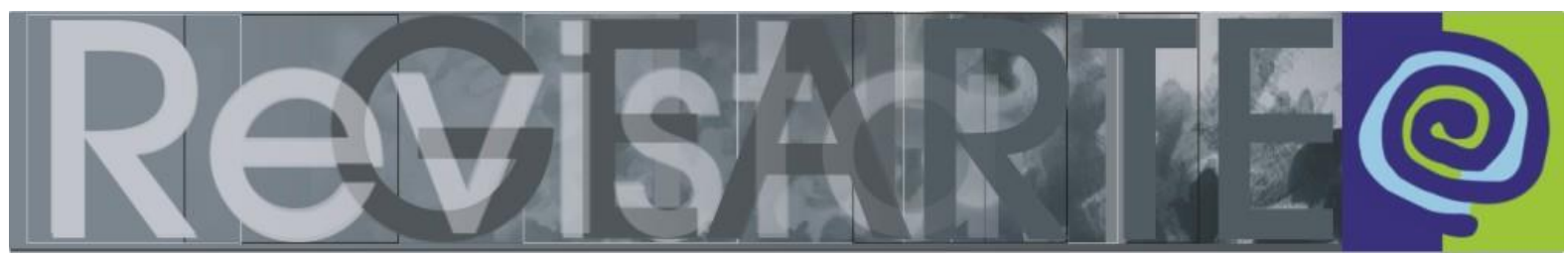

ISSN 2357-9854

\title{
Corpo que paira, corpo que flui: corporeidades múltiplas na arte-vivência
}

\author{
Rosália Menezes (Universidade da Integração Internacional da Lusofonia Afro- \\ Brasileira - UNILAB, Redenção/CE, Brasil)
}

Jo A-mi (Universidade da Integração Internacional da Lusofonia Afro-Brasileira UNILAB, Redenção/CE, Brasil)

RESUMO - Corpo que paira, corpo que flui: corporeidades múltiplas na arte-vivência - O objetivo deste artigo é apresentar reflexões críticas a propósito das relações entre o Corpo e os seus agenciamentos com o mundo (compreendido como corporeidade), mantendo com as experimentações artísticas um viés estratégico de territorialidade crítica enquanto "linha de fuga" - conforme Deleuze. Teoricamente, teceu-se um percurso que se iniciou com as perspectivas do corpo na clássica filosofia ocidental, entremeado por estudos de base sociológica (na discussão do processo civilizador e do corpo como coletividade) e de base histórica (do corpo contextualizado em sua relação com o mundo e com as artes). Assim, a arte-vivência com o corpo, aqui demonstrada, procurou constituir-se em corporeidades cuja travessia foi reconstruindo conceitos, percepções e ações sobre o corpo cena-emsi: objeto e ato de experiências artístico-pedagógicas.

PALAVRAS-CHAVE

Corpo. Corporeidade. Arte-vivência.

ABSTRACT - A body that hangs, a body that flows: multiple corporate in art-experiences - The aim of this article is to present critical reflections on the relations between the Body and your agencies with the world (understood as corporeity), maintaining with the artistic experiments a strategic bias of critical territoriality as a "line of escape" - according to Deleuze. Theoretically, it was made a course began with the perspectives of the body in classical Western philosophy, interspersed by sociological (in the discussion of the civilizing process and the body as a collectivity) and historical studies (from the body contextualized in its relation to the world and with the arts). Thus, the art-experience with the body, demonstrated here, sought to be constituted as corporeities whose crossing was reconstructing concepts, perceptions and actions on the body scene-in-itself: object and act of artistic-pedagogical experiences.

KEYWORDS

Body. Corporeity. Art-experience.

A intenção deste trabalho é problematizar as questões relativas ao corpo em seus incontornáveis agenciamentos com o mundo, partindo de um enfoque que situa a noção de corpo como construção filosófica, histórica e sociocultural em seu aspecto dinâmico-relacional com experimentações artísticas. As experimentações artísticas servem, aqui, enquanto viés estratégico, fluência que explora poéticas e estéticas como possibilidades de desconstrução e resistência, vetores ativos que transformam o corpo em corporeidade. A corporeidade funciona como agente catalisador que 
instaura uma rede relacional, envolvendo e interligando sensorial, pulsional, motor e simbolicamente contextos e práticas coletivas (BERNARD, 1990). Nesse sentido, os compartilhamentos e as trocas entre corpo e mundo acontecem em processos que enredam dinâmicas espaciais, fluxos de sentidos, práticas culturais e comunitárias; instâncias coletivizantes e agregadoras que fazem do corpo parte de uma disposição amplificada de ser-em-si-com-o-outro, numa perspectiva cósmica e ampla com o mundo (MAFFESOLI, 1985) - o corpo, assim, não se evidencia numa unidade totalizante, mas enquanto elemento que compõe um universo com outros elementos: uma relação, portanto, cambiante e recíproca com o seu redor.

\section{O Corpo É Múltiplo...}

O legado da tradição clássica de pensamento ocidental-europeizante deixounos o legado do dualismo na medida em que o pensamento socrático-platônico fundou a separação hierarquizante entre corpo e alma. A doutrina platônica pensou a inferioridade do sensível em relação ao inteligível, isto é, refletiu que tudo que está relacionado ao corpo e às paixões, ao mundo sensível, é hierarquicamente inferior à instância das idealidades impalpáveis, ao mundo inteligível - que Platão denominou de "Mundo das Ideias". A alma, para Platão, preexistia ao corpo (material, mortal e sem inteligência), sendo imortal, divina e imaterial. Assim, o corpo, ligado aos desejos e paixões amorosas, representava, ao mesmo tempo, túmulo e cárcere da alma, ou como nos diz Platão no Fédon: o "corpo é prisão da alma".

Habitando o mesmo horizonte histórico, Aristóteles guardou uma diferença bastante significativa em relação a Platão no que concerne ao entendimento da alma como ligada ao corpo pelos laços da vida. Para Aristóteles, o ser humano está próximo da natureza e sua alma é uma forma do corpo, um princípio de vitalidade que está imiscuída na natureza; como todos os seres vivos, as pessoas possuem alma e corpo - sendo este animado pelos dinamismos da forma, isto é, o corpo seria habitado pelos movimentos da alma (núcleo da dimensão inteligível do ser humano): "revela-se que, na maioria dos casos, a alma nada faz sem o corpo, como, por exemplo, irritar-se, persistir, ter vontade e perceber em geral; por outro lado, parece ser próprio a ela particularmente o pensar" (ARISTÓTELES, 2007, p.47). Aristóteles compreende o ser 
humano como animal político e sua realização maior seria o exercício da ética e da política em comunidade.

Dividido ou em consonância com a alma, o corpo constituiu-se na Antiguidade clássica ocidental pelo justo equilíbrio entre proporção e simetria; dispunha-se o corpo em sua metonímia individual, como representante de uma episteme filosófico-social da Beleza: ordem paradoxal que se instaura, em sua última fase, sob a égide da grandeza apolínea, um "sublime conceitualismo do intelecto e da arte ocidentais", "linha traçada contra a natureza" dionisíaca cuja força ctônica ampliava-se nos travestismos de um pathos incontrolável (PAGLIA, 1992, p.78-92). As esculturas, as inscrições nas paredes e os vasos bem representavam essa ordem paradoxal, contando histórias dos deuses gregos, dos atletas olímpicos, das tragédias encenadas, do cotidiano das pessoas.

Na Idade Média, o Corpo está, oficialmente, esquadrinhado por uma arte e pensamento oficiais cujos modelos filosófico-dualistas reafirmam as duas escolas gregas da Antiguidade: de um lado, o pensamento platônico em Santo Agostinho, de outro, a força aristotélica em São Tomás de Aquino. Indubitavelmente contraditório, contudo, o corpo medieval é sagrado e profano: modelo de corpo altamente honrado do Cristo (o único digno de inspiração) de um lado; corpo carnavalesco da festa e da zombaria, de outro (BAKHTIN, 1999). Uma luta constante para domar o corpo carnavalesco, infligindo-Ihe "uma feroz disciplina, imaginando e aplicando-lhe as coações mais dolorosas", pois "todos aqueles que desprezam o corpo e rejeitam este mundo terrestre esperam de fato adquirir o mérito santificante" (GÉLIS, 2008, p.55).

A partir do Renascimento, na Modernidade, o corpo torna-se objeto visual que só tende a se prolongar como cena-em-si. A anatomia humana erige-se numa das grandes realizações da arte renascentista - arte matemática das perspectivas -, subsidiada pelo dualismo psicofísico de René Descartes. Buscando compreender a natureza humana e tendo como ponto de partida as regras do método, Descartes dividiu o ser humano em res cogitans e res extensa, isto é: coisa pensante (uma substância, um eu, uma alma) e coisa extensa (corpo). No sistema cartesiano há uma oposição radical entre interioridade pensante (sujeito) e a exterioridade do corpo (objeto), de modo que o eu pensante não necessita de lugar algum nem depende de 
coisa alguma material para pensar e existir (DESCARTES,1982). O dualismo psicofísico de Descartes, alavancado por um binarismo radical, dá continuidade a toda uma tradição histórico-cultural que reforça o dualismo como modelo valorativo de interpretação da existência humana. Foi pautado por essa tradição - onde se imiscuem filosofias e religiões - que a noção de corpo ocupou um lugar secundário e subalterno: desprovido de inteligência, o corpo e seus instintos são representados como uma dimensão irascível que liga homens e mulheres a sua natureza animal e inferior.

Essas representações vivenciais do corpo, em suas notas histórico-sociais, foram fortemente campeadas, ainda, pelo processo civilizador de que fala Norbert Elias (1993) através da constituição do Estado, o autocontrole, as redes de interdependência na vida social, a moderação das emoções e a rigorosa divisão das funções sociais que passam a configurar a existência social, e, por conseguinte, dos fluxos do corpo na Modernidade. Essa força civilizatória sobre o corpo é "mantida em movimento pela dinâmica autônoma de uma rede de relacionamentos, por mudanças específicas na maneira como as pessoas se veem obrigadas a conviver" (ELIAS, 1993, p.195). Ora, se por um lado o processo civilizatório se impõe enquanto necessidade contra as "barbáries" sociais recalcitrantes de sociedades coletivistas que "se veem obrigadas a conviver" com execuções contra vidas humanas em praças públicas, por outro, sedimenta-se rastreado por uma série de monopolizações nas estruturas centrais dessas sociedades, cujo papel da vigilância social individualizada torna-se essencial para manutenção da nova ordem social:

Só com a formação desse tipo relativamente estável de monopólios é que as
sociedades adquirem realmente essas características, em decorrência das
quais os indivíduos que as compõem sintonizam-se, desde a infância, com
um padrão altamente regulado e diferenciado de autocontrole; só em
combinação com tais monopólios é que esse tipo de autolimitação requer um
grau mais elevado de automatismo, e se torna, por assim dizer, uma
"segunda natureza" (ELIAS, 1993, p.197).

Esses padrões de autocontrole e autolimitação recorrentes no processo civilizador ocuparam as memórias das sensações corporais vividas desde a infância, de tal modo, que ainda permanecem em nossos registros mentais e corporais e persistem em nossas vidas a ponto de pautar grande parte de nossas limitações comportamentais: numa espécie de disciplinamento constante em direção à ordem social instituída. 
O corpo-modelo da Modernidade, assim, obedece ao rigor científico-cartesiano e civilizador construídos no ocidente-europeizante sob força consciente dos padrões de comportamento e controle social; corpo-modelo muito bem retratado desde as madonas de Rafael, nos corpos nus e dóceis pousantes dos ateliês, nas pinturas de família das elites à convivência social sob paisagens bucólicas nos verdes jardins europeus. De acordo com Michaud (2011), os corpos modernos civilizados e mecanizados foram amplamente trabalhados pelas diversas linguagens artísticas que, apropriando-se das descobertas e das formas de pensar de seu tempo, ressignificaram seus formatos e paradigmas - é o caso, muito especialmente, da experimentação com a Imagem a partir da fotografia e do cinema nos séculos XIX e XX.

$\mathrm{Na}$ contemporaneidade, a "perfeição" do corpo mecanizado engendra-se, paradoxalmente, a uma volatilização inconstante e instantânea: se por um lado podemos ver o corpo mecanizado refletido no desenvolvimento de uma cultura do esporte, da guerra, da indústria e da engenharia biotecnológica (em cirurgias estéticas, dietética, body-building, doping, clonagem), por outro, encontramo-lo afronteiriço e volátil em experiências de democratização da pornografia, de autoexibicionismo em redes sociais, de espetacularização da vida privada e de autorrepresentação. $O$ corpo contemporâneo, embora ainda mecanizado, parece se liquefazer numa corporeidade cujo fluxo pigmenta-se do instantâneo:

[...] a duração histórica é identificada com a gravação instantânea (e a princípio apagável); obras de arte, um dia pensadas para durar "além do túmulo", são substituídas por happenings deliberadamente curtos e por instalações que pouco duram; identidades de um tipo pensado para ser construído com zelo e para durar por toda uma vida são trocadas por kits de identidade para montagem imediata e desmantelamento igualmente instantâneo (BAUMAN, 2008, p. 287).

No mundo contemporâneo, ou por vezes denominado pós-moderno, a história do corpo vai ganhando novos tons, afinal, a vida tem potência infinita de variação e a história do corpo é a história de uma crise instaurada, um abalo sísmico que circula das entranhas da cultura à superfície da pele. "A cultura se constrói no trânsito entre o individual e o coletivo, entre o dentro e o fora do corpo, operando ao mesmo tempo num continuum entre emoção, razão, ação corpórea incluindo a aptidão para conceituação [...]" (GREINER, 2005, p.103). Ao lado dos corpos disciplinados em 
cultos religiosos e escritórios higienizados, há os corpos estetizados (na Body Art) e modificados com próteses e intervenções cirúrgicas - o que Francisco Ortega (2008) chamou de "anatomias pós-modernas", por vezes, palco de performances artísticas.

Permeado por todos esses entroncamentos filosóficos, históricos, socioculturais e pela compreensão do corpo como corporeidade, pretende-se mostrar, a seguir, experiências de prolongamentos do corpo enquanto sujeito e objeto do ato artístico, o corpo cena-em-si que utiliza, no ensino e na vivência das artes, múltiplas formas de existência.

\section{Experiência na Universidade: superando muros}

Como realizar uma pesquisa em arte que opere para além da clausura e do controle dos métodos e conhecimentos disciplinares? Como abrir passagens para além dos modelos tão encharcados pelo dever-ser-acadêmico? E como vivenciar o corpo enquanto "sujeito e objeto do ato artístico", ponto de ancoragem para um vir-aser ainda possível de ser pensado (MICHAUD, 2011, p.562-563)?

O registro dos modelos e conhecimentos disciplinares acontece nos processos educacionais, de modo geral, e nas universidades, de modo específico, exercendo um importante papel de perscrutadores do condicionamento social. Nas instituições de ensino, por vezes, vemos ascenderem abordagens culturais reificantes, experiências moldadas pelos clichês e estruturação de conhecimentos massificadores. Ora, se são as instituições de ensino uma das principais redes de estabelecimento do controle, disciplina, vigilância e ordenamento alienante dos corpos (juntamente com as religiões, mass media, Estado), então é necessário quebrar-por-dentro tais estruturas, (pro)evocar o que está estabelecido a partir do núcleo, esfacelar sem destruir - porque há muitas experiências criativas, libertárias e autônomas que precisam ser multiplicadas nos processos de (des)educação dos corpos nas instituições de ensino.

Assim, nesse território do fazer/ensinar através/com artes tem-se procurado: a) buscar estratégias que possam atravessar e redimensionar os formatos e modelos mecanizados pela excessiva disciplinarização dos currículos, dos espaços, dos conteúdos e das narrativas institucionais; b) traçar um novo sentido sobre as 
regularidades do plano de aula do semestre anterior, tecendo-lhe numa "linha de fuga" - à maneira de Deleuze, para quem a linha de fuga é, ainda, uma desterritorialização, uma linha ativa. A fuga torna-se um componente da linha, uma maneira de encontrar e provocar instabilidades em um sistema demasiado ordeiro e uniforme (DELEUZE, 1998) - movimentos que procuram contornar e atravessar situações estruturais, modelares e, por vezes, maniqueístas, permeadas por modelos encarcerados em formas pré-estabelecidas e pertencentes à ordem do programável (em categorias como família, sexualidade, trabalho, formação profissional).

A "linha de fuga" funciona como um operador conceitual que possibilita traçar mapas de instabilidade precária e de contornos móveis, pois nas experimentações artísticas os procedimentos de composição e as metodologias precisam funcionar como ferramentas de auxílio no constructo dos artefatos artísticos. A imprevisibilidade do objeto artístico solicita, desta forma, uma maior plasticidade das ferramentas e das estratégias metodológicas em seus planos, texturas, movimentos, gestos, cores, palavras e poéticas - de outro modo, poderíamos incorrer nas certezas reprodutoras de identidades que só ajudariam a corroborar para a manutenção de uma ordem

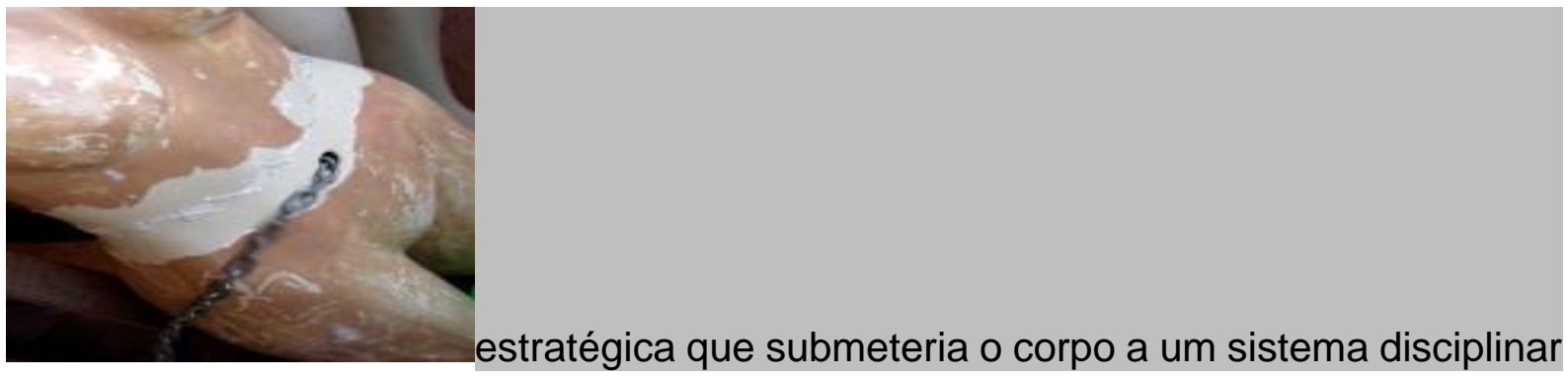

organizado, produtivo e submisso
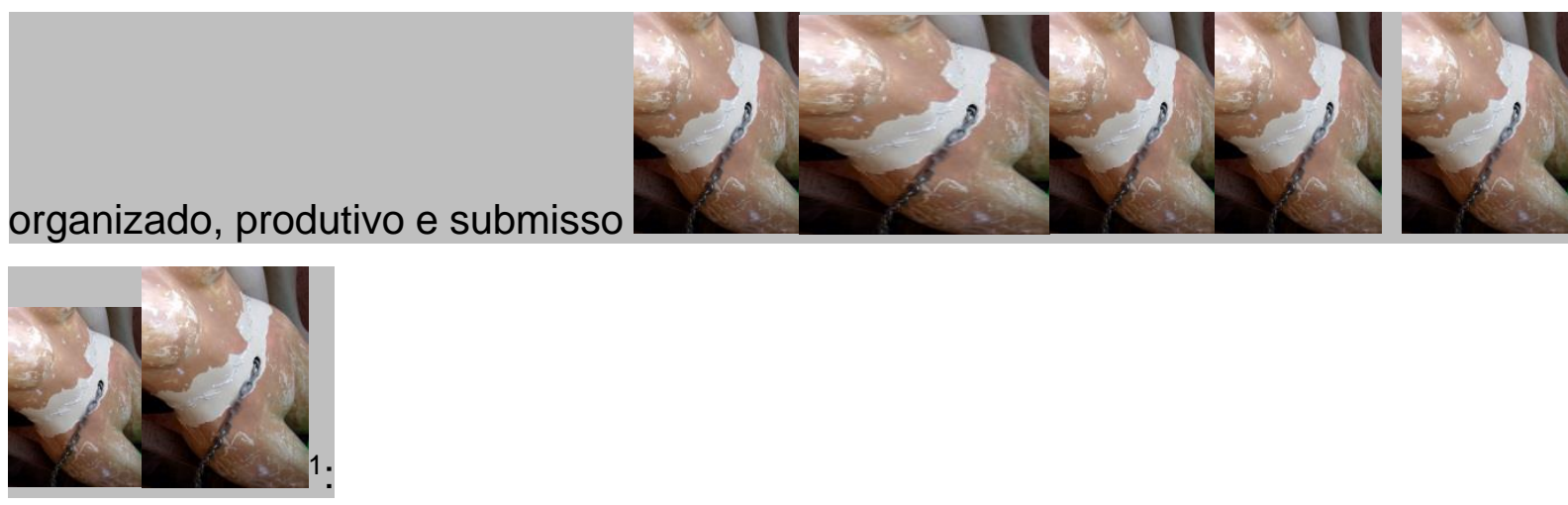

1 Estas imagens fotográficas estão assim dispostas para sugerirem uma conexão conceitual com a tessitura do escrito e fazem parte do ensaio fotográfico do projeto "Territórios Errantes" (a ser explicitado posteriormente). 
A manutenção de uma "ordem" e a regulamentação de um "sistema disciplinar" são duas formas de tecnologia do poder, instrumentos de correção e manipulação do corpo, pois "(...) as relações de poder têm alcance imediato sobre ele; elas o investem, o marcam, o dirigem, o supliciam, sujeitam-no a trabalhos, obrigam-no a cerimônias, exigem-Ihe sinais" (FOUCAULT, 2004, p.25). Assim, uma das formas de "linha de fuga" na universidade seria construir ações de desterritorialização dos corpos enquanto imersão no exercício da corporeidade, manobra de resistências estética e política - fazendo com que o corpo seja um afluente para a condução e prolongamento da obra/objeto de arte em variadas dimensões.

Nesse sentido de corpo-afluente e corpo-condução, registre-se uma experiência artística realizada sob o título "Superando Muros". Essa teve como objetivo reunir o público advindo da comunidade universitária, em dois turnos de oficina, para intervir nos muros externos da universidade com técnicas do grafite, estêncil, pintura e colagem. O mote para a interferência teve por base as discussões epistemológicas do feminismo na contemporaneidade. Abaixo, fotos (1 e 2) da intervenção artística:

Foto 1

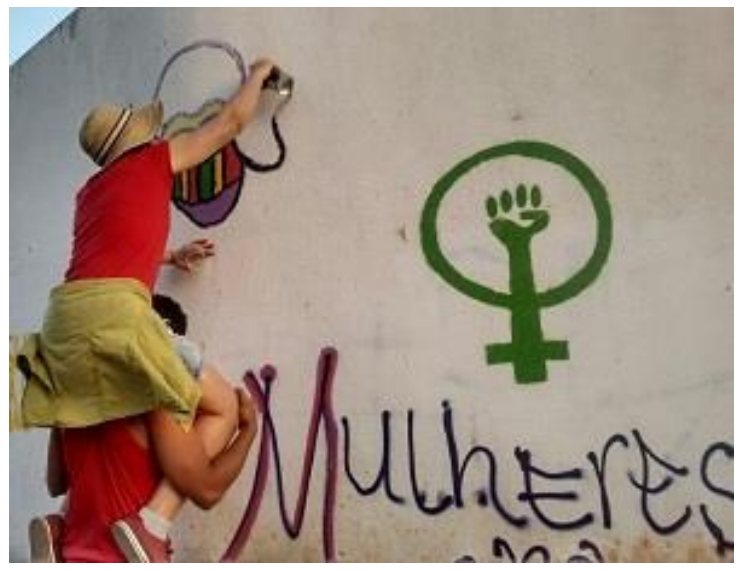

Fonte: arquivo das autoras.
Foto 2

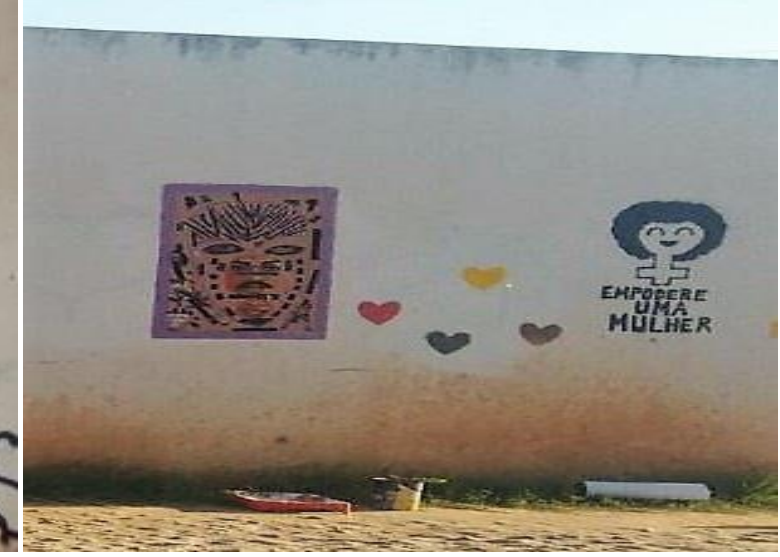

Fonte: arquivo das autoras.

Os experimentos com a velocidade e densidade dos sprays, o trabalho coletivo dos corpos (segurando cartazes, cortando ranhuras, suportando o peso um do outro em escadas humanas) e suas colorações (mãos, pés, rostos pintados com o espargir das tintas e do spray), a dança e o manejo inspirados pelas músicas no momento da estruturação do material a ser exposto e a ocupação dos corpos em espaço público 
fizeram de "Superando muros" uma arte-vivência com o corpo físico e corpomovimento; corpos-em-ação que se coadunaram com o seu redor, influenciando e sendo influenciado pela matéria e pela memória de suas ações, permitindo que o "outro" refletisse e fosse refletido nessas interferências espelhares (BERGSON, 2006).

\section{O Fazer Artístico Além da Universidade: territórios errantes}

O conceito de território é amplo e diversificado. São múltiplas as possibilidades de uso do termo. A geografia tradicional pensa o território exclusivamente em sua dimensão "naturalista", num sentido físico, e, segundo a perspectiva adotada por Milton Santos, valorizando mais os "fixos" que os "fluxos" - tendo a preponderância de uma visão política do território, acontecendo sob ponto de vista estatal. No entanto, é possível pensar o conceito de território imiscuindo a dimensão física e política aos contextos simbólicos e afetivos, interligando lugares e pessoas que operam em conjunto, articulando estratégias que compõem as dinâmicas do cotidiano (HAESBAERT, 2002).

Desta maneira, "Territórios Errantes" tornou-se um conjunto de ações artísticas em processo desde 2010, realizada em espaços públicos de uma cidade do país. A "errância" adjetiva o traço nômade do próprio experimento artístico, isto é, o nomadismo que se configura como procedimento estético e, ao mesmo tempo, como operador conceitual no processo de composição da ação artística. A construção de uma ambiência performativa tem sido o componente catalisador e aglutinador dessa ação artística: assim, o primeiro passo na construção dessa ambiência performativa foi marcado pela instalação de uma espiral feita de tecido - uma espécie de centro fictício da Praça da Feira. O movimento da espiral como convocação à imagem da abertura ao mundo,

[...] oposto ao simbolismo do círculo; este é religioso, teológico, aquela como círculo desviado para o infinito, é dialética: na espiral, as coisas voltam, mas em um outro nível: há retorno na diferença, não repetição na identidade; [...] graças a ela, não somos obrigados a pensar: tudo foi dito, ou: nada foi dito, nada é primeiro, no entanto, tudo é novo (BARTHES, 1990, p. 198). 
O segundo passo consistia em instalar, no centro da espiral, uma tigela transparente contendo água. Pouco a pouco, os objetos distribuídos pelo espaço iam formando uma Instalação no interior da praça, com pão e vinho sendo servidos para aqueles e aquelas que se achegassem ao local.

Depois, uma provocatória para cada visitante: percorrer a espiral de tecido e "tingir" a água com vinho; comer pão, beber vinho, caminhar em espiral e fazer uma oblação na intenção de um fazer-com que se desdobrou, misturou e reinventou nos diversos "textos" produzidos pela Praça, promovendo trocas intensivas entre corpos e fluxo urbano. Nesse sentido, pode-se lembrar da reflexão que Espinoza fez em sua Ética e que permanece pairando sobre nós: "o que pode o corpo?" Ora, segundo este filósofo, o corpo pode ser compreendido como uma relação de afetos e de intensidades que se comunicam entre si:

[...] composto de um grande número de indivíduos (de natureza diversa) cada um dos quais é também muito composto. Os indivíduos que compõem o corpo humano e, consequentemente, o próprio corpo humano, são afetados de numerosas maneiras pelos corpos exteriores (ESPINOZA, 1997, p. 240).

Os objetos utilizados em "Territórios Errantes" foram objetos manufaturados (tecido, tigela de acrílico, jarra e copos de vidro, peneira e jogo de letras) e a recondução desses objetos no contexto da ação artística pôde gerar uma collage, ou seja, um processo de construção que justapôs imagens, objetos e até mesmo situações libertando-os de suas funções ordinárias, criando paradoxos visuais ao deslocá-los de seu contexto original: um ato "por si só entrópico e lúdico" (COHEN, 2007, p. 60).

Fecha-se a cena. Abram-se as fotos 3 e 4 (retiradas na feira da Praça): 
Foto 3

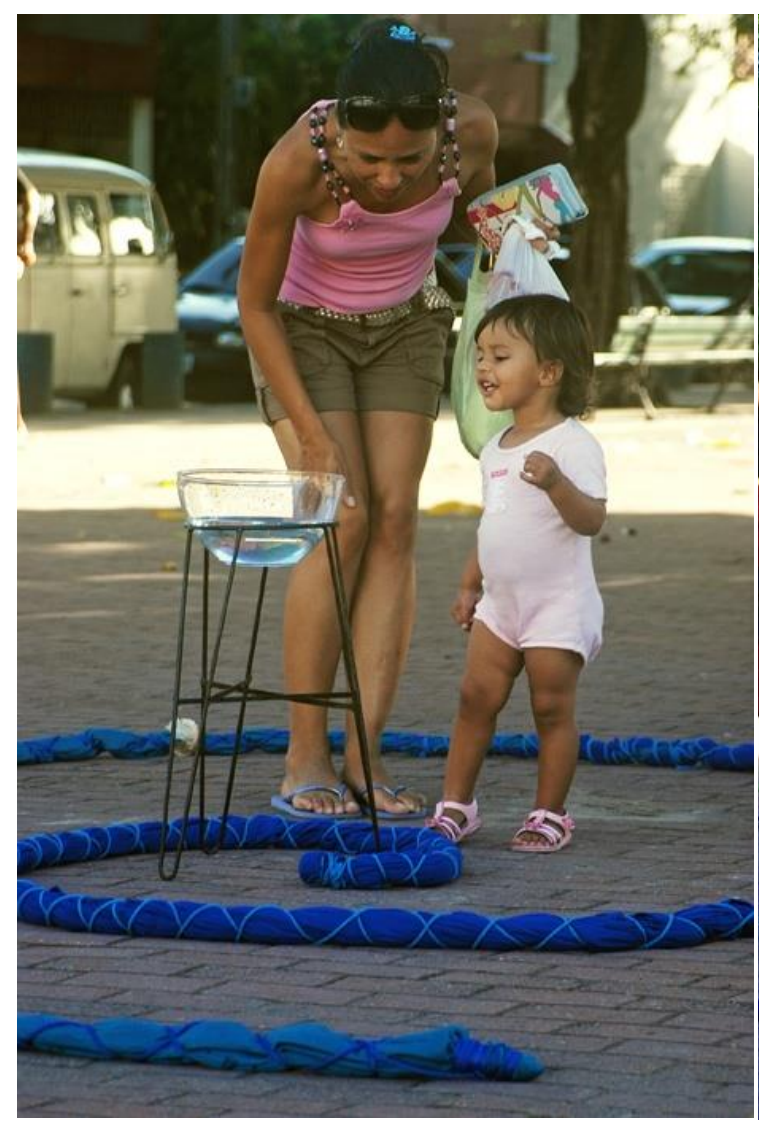

Fonte: arquivo das autoras.

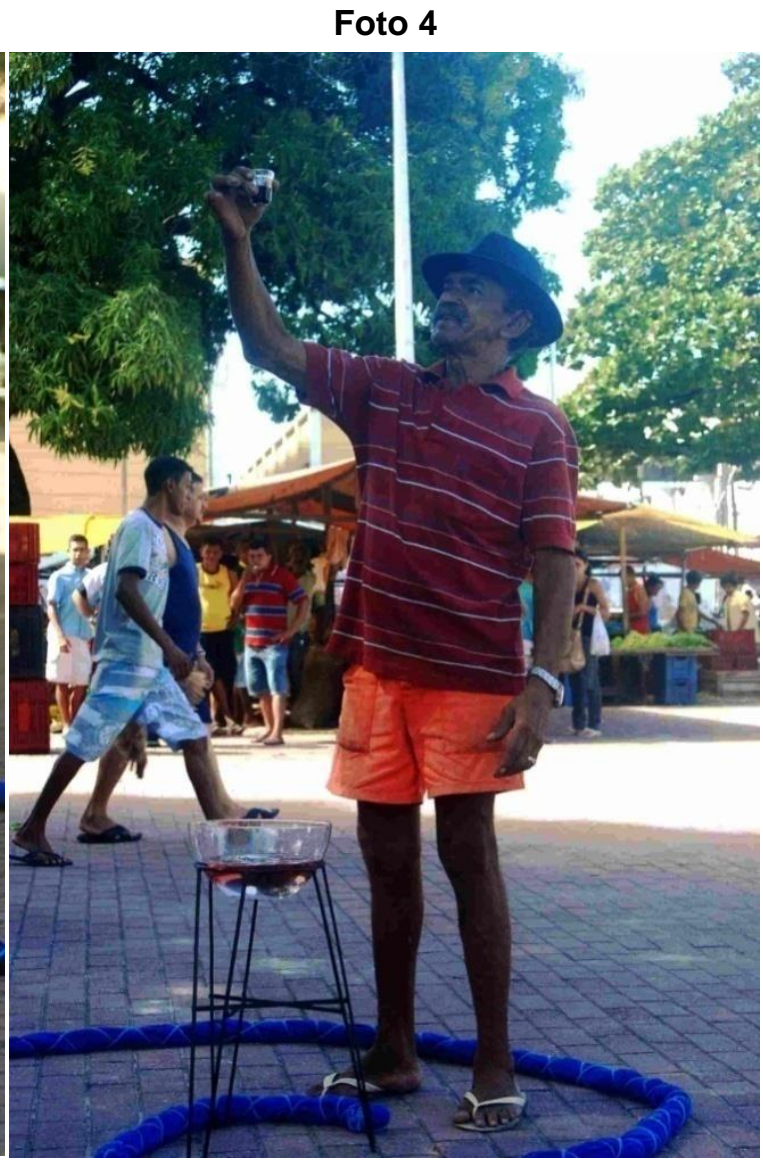

Fonte: arquivo das autoras.

Por fim, a proposta desse experimento artístico não se vincula à ideia de levar arte e cultura para feirantes da praça que não disponibilizam de tempo e dinheiro para se deslocarem até os museus, salas de teatro ou galerias. Pensado como experimento artístico performativo que se realiza entre lugares, "Territórios Errantes" configura-se num vetor de ação estético-político que pretende atuar muito mais nas frestas, nos escapes, nos deslizes que desestabilizam corpos e ambiente; o público ali presente participou ativamente da experiência, olhando, tocando, comendo e bebendo, falando bem de perto, perguntando e, às vezes, hesitando - alguns mais de longe desconfiavam daquela invasão no repertório cotidiano da praça - mas com uma presença que se imiscuiu ao objeto artístico, modificando, interpretando, desconstruindo signos e inventando seus significados próprios. Essas estratégias cênicas, a partir das relações de (des)encontros com pessoas no espaço público urbano, tornaram-se errâncias artísticas que, provavelmente, mantiveram alguma nostalgia com o homo ludens e suas relações de transitoriedade com a vida: o corpo nômade de si mesmo, cujo jogo de forças em devir, território em constante estado de 
exploração, foi traçando indefinidamente novos percursos de invenção e surpreendendo com sua potência de permeabilidade em engendrar soluções provisórias, expandir conceitos e compartilhar afetos na instabilidade do tempo presente.

\section{Considerações Finais}

O corpo esburaca a pele do mundo. O mundo deixa-se sobre o corpo invadindoo, disseminando seus cheiros, modos, gostos, traçando percursos, criando ritmos. A pele do corpo é uma máscara porosa de dupla face, um dentro-fora, uma profundidade de superfície. Pele-carne-osso-fluxos, múltiplo de forças que afeta e é afetado pelo espaço-tempo da vida: "A pele é um elemento essencial, porque paradoxal: interface entre o espaço exterior e o interior, constitui o operador do fundo do corpo na superfície" (GIL, 2002, p. 141).

$\mathrm{Na}$ contemporaneidade, nosso corpo está cada vez mais estudado, conceituado, idealizado, tornado visível, objeto de adoração e consumo. Convergir, divergir e desestabilizar: o corpo poroso torna-se via de fluxo entre os sentidos e o mundo; um reservatório de memórias que nunca estão sozinhas ou estáticas, pois com o corpo há sempre gestos, falas, desejos, consciências.

A arte-vivência com o corpo, aqui demonstrada, procurou constituir-se em corporeidades cuja travessia foi reconstruindo conceitos, percepções e ações sobre o corpo cena-em-si: objeto e ato de experiências artístico-pedagógicas como ações de resistências estético-políticas. Um corpo coletivo e coletivizante - um fluxo entre subjetividade e mundo com uma consciência filosófica quase conciliatória: por vezes, apolíneo, resistente, direcionado, integrador nas ações rotineiras; por outras, dionisíaco, engendrador, criativo, imerso voluptuosamente nas contradições do cotidiano. Por fim, um corpo-mundo que atravessa o tempo nele mesmo.

\section{Referências}

ARISTÓTELES. De anima. Tradução de Maria Cecília Gomes dos Reis. São Paulo: Ed. 34, 2007. BAKHTIN, Mikhail. A cultura popular na Idade Média e no Renascimento. São Paulo: Hucitec, 1999. BARTHES, Roland. O óbvio e o obtuso: ensaios críticos III. Rio de Janeiro: Nova Fronteira, 1990. 
BAUMAN, Zygmunt. Sobre os usos pós-modernos do sexo. In: BAUMAN, Zygmunt. A sociedade individualizada: vidas contadas e histórias vividas. Rio de Janeiro: Zahar, 2008. p. 275-297

BERNARD, Michel. Les nouveaux codes corporels de la danse contemporaine. In: PIDOUX, Jean-Yves. La danse, art du XX ème siècle? Lausanne: Editions Payot, 1990

BERGSON, Henri. Matéria e memória: ensaio sobre a relação do corpo com o espírito. São Paulo: Martins Fontes, 2006.

ESPINOSA, B. Ética. São Paulo: Nova Cultural, 1997. Coleção Os pensadores.

COHEN, Renato. Performance como linguagem. São Paulo: Perspectiva, 2007.

DELEUZE, Gilles. Dialogues. São Paulo: Escuta, 1998.

DESCARTES, René. Discurso do método. São Paulo: Abril Cultural, 1979.

ELIAS, Norbert. O processo civilizador. v.2. Rio de Janeiro: Zahar, 1993.

FOUCAULT, Michel. Vigiar e punir. Petrópolis/Rio de Janeiro: Ed. Vozes, 2004.

GÉLIS, Jacques. O corpo, a igreja e o sagrado. In: CORBIN, Alain; COURTINE, Jean-Jacques; VIGARELLO, Georges (Org.). História do corpo: da Renascença às Luzes. Rio de Janeiro: Vozes, 2008. p. $19-130$.

GIL, José. O corpo paradoxal. In: LINS, Daniel; GADELHA, Sylvio (Org.). Que pode o corpo. Fortaleza: Relume Dumará, 2002. p.131-147

GREINER, Christine. O corpo. São Paulo: Annablume, 2005.

HAESBAERT, Rogério. Territórios alternativos. São Paulo: Contexto, 2002.

MAFFESOLI, Michel. A sombra de Dionísio. Coleção tendências. v. 7, Rio de Janeiro: Graal, 1985.

MICHAUD, Yves. Visualizações - o corpo e as artes visuais. In: CORBIN, Alain; COURTINE, JeanJacques; VIGARELLO, Georges (Org.). História do corpo: as mutações do olhar - o século XX. 4. ed. Rio de Janeiro: Vozes, 2011. p. 541-565

ORTEGA, Francisco. O corpo incerto: corporeidade, tecnologias médicas e cultura contemporânea. Rio de Janeiro: Garamond, 2008.

PAGLIA, Camille. Apolo e Dioniso. In: PAGLIA, Camille. Personas sexuais: arte e decadência de Nefertite a Emily Dickinson. São Paulo: Companhia das Letras, 1992. p. 77-100.

PLATÃo. Fedro. Tradução de Carlos Alberto Nunes. Belém: UFPA, 2001.

SANTOS, Milton. A natureza do espaço: técnica e tempo, razão e emoção. São Paulo: Hucitec, 1996. 


\section{Rosália Menezes}

Professora adjunta da Universidade da Integração Internacional da Lusofonia Afro-Brasileira. Possui graduação em Filosofia pela Universidade Estadual do Ceará - UECE, formação em Teatro pelo Instituto Federal de Educação, Ciência e Tecnologia do Ceará, IFECE em parceria com a Escola Pública de Teatro da Vila das Artes, mestrado em Filosofia pela Universidade Federal do Ceará - UFC, doutorado em Educação pela Universidade Federal do Ceará (2011). Participa dos grupos de pesquisa (CNPq) em Filosofia e linguagem artísticas modernas e contemporâneas e Drama, dramaturgia, cena: questões contemporâneas. Atua nas áreas de Artes Cênicas, Filosofia e Educação, realizando pesquisas que privilegiam uma interface entre as mesmas.

E-mail: mariarosa@unilab.edu.br

Currículo: http://lattes.cnpq.br/4614654109148320

\section{Jo A-mi}

Professora-pesquisadora da Unilab-CE, trabalha com pesquisas e projetos de extensão nas áreas de "Literatura e Artes Visuais", "Literaturas contemporâneas de Língua Portuguesa", "Relações de Gênero". É coordenadora do ATELIÊ - grupo de pesquisas e estudos interartes -, membro do Comitê de Ética em Pesquisa com Seres Humanos e integrante do Núcleo de Políticas de Gênero e Sexualidade. Como escritora, publicou a ficção intitulada "Cor Adormecida" (2012) e ganhou menção honrosa pelo conto "O cabrito beija-flor", no XV Prêmio Estadual Ideal Clube de Literatura. Enquanto artista visual, participou de exposições, instalações coletivas e dirigiu o documentário "No Ceará dos grafites" (disponível no YouTube)

E-mail: joami@unilab.edu.br

Currículo: http://lattes.cnpq.br/0945228363295282 